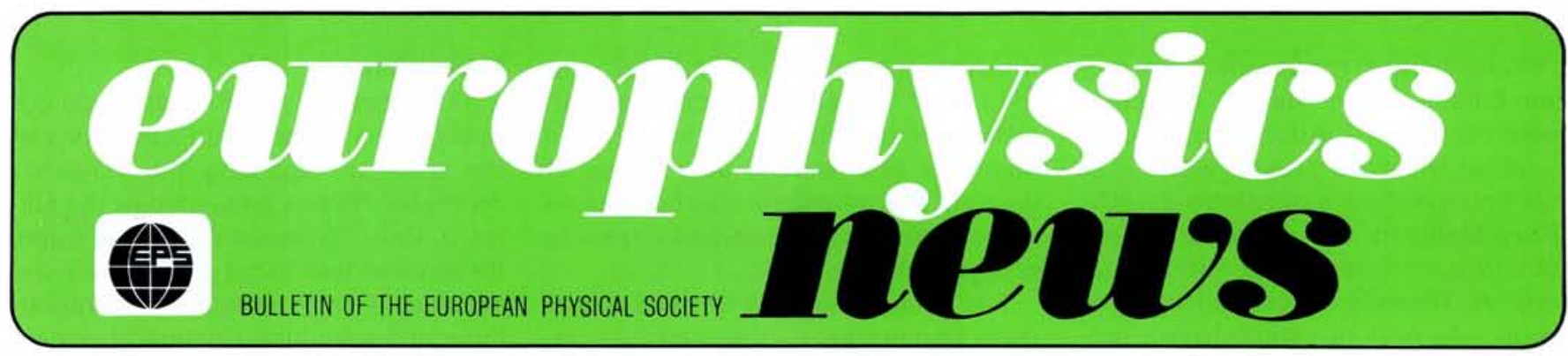

J.A.

Volume 20

Number 5

May 1989

\title{
EPS Awakes
}

Not everyone finds the month of March to be ideal for an annual meeting, particularly when Winter seems to have installed itself permanently and the world appears composed entirely of shades of grey. How different this year when not only outside in Zagreb was Spring in evidence, but in the meetings too, especially that of the EPS Council where the stirrings of last year began to gather momentum as EPS collectively shrugged off the sclerosis of its advancing years and resolved to plan an invigorating future.

This does not mean we have overnight resolved our besetting problems. Limited funds are a serious handicap to expansion and we have to go out and look for other sources and establish relations with other bodies which do have funding but presently lack the infrastructure that EPS can provide. If we do not do this then the opportunities will pass us by and we shall find our Divisions, for example, just organising a few conferences of limited topicality. One could note how few EPS Study Conferences were currently in the calendar, yet these were the type of meeting needed more than the special subject meetings, which proliferated in some fields. In contrast the new joint European Advisory Committee between EPS and ROSTENA (q.v.) showed what could be done.

Our own structure had been created in the early days of EPS and we had to look at this again and see if it was entirely appropriate today. One noted the surge in Interdivisional Groups which was clearly a healthy sign and the projects in the Advisory Committees which might benefit from a more flexible administration.

With these sorts of question in mind, the President had taken the initiative to set up a Review Committee to study where we should be going. Under his Chairmanship it included A. Daneels, M. Jacob, W.J. Merz, R.A. Salmeron plus the Executive Secretary and it was then agreed to invite a delegate of the IOMs and someone from an eastern country (this last pushed very hard by a member from (srael). In addition, the Presidents of our member societies were being invited to participate in a brain-storming in Eindhoven in June. The Executive Committee was meeting there in view of the Conference being held to celebrate the 80th birthday of H.B.G. Casimir entitled "Between Science and Technology".

Apropos our group members, it was announced, to applause, that S. Kapitza (a former member of the Executive Committee) had been leading a study in the USSR aimed at creating a national physical society whose membership would not be confined to the Academy of Sciences. It would be structured more on the lines of western societies and advice would be welcomed from EPS members.

\section{Divisions}

It was disappointing that so few Chairmen of Divisions had come to Zagreb - noone from the Astronomy and Astrophysics Division, the Interdivisional Computational Physics Group, the Condensed Matter Division, the Optics Division or the Plasma Physics Division - the last because of the clash of their annual conference. No doubt the advance circulation of the President's report was a factor, but this only emphasises the point made in Council that organizing a conference every year, or every few years, should not be considered sufficient. Small wonder that the members of Divisions were beginning to react against the inertia and the lack of communication evident in some Divisional and Section Boards.

At least the High Energy and Particle Physics Divisional Board acted as the Programme Committee for its biennial conference and as W. Bartel explained had been making positive efforts to cooperate fully with IUPAP and the American Physical Society to avoid duplication. It was also supporting the application of the accelerator designers to form an Interdivisional Group and was presenting its proposals for rules to govern the award of an EPS HEPP prize which Council, after making a few suggestions, approved.

In stark relief was the extensive programme of the Interdivisional Group on Experimental Physics Control Systems which had as its latest recruit a laboratory from Beijing, to bring the total to 24 . The majority of Council saw no problem

\section{Contents}

EPS Awakes

Seminar on International

Research Facilities

Applied Physics in Nice

Muon Catalysed Fusion

The Non-Stick Pan

Electron Scattering with

Photoelectrons

64

H-P Prize Call for Nominations

67

Computers in Teaching

68

New EPS Members

Molecular Dynamics Simulations of Disordered Materials

Meetings Up-date 
in having member laboratories from outside Europe nor in having non-Europeans coopted to the Board. In any case - other Divisions please note - all their Board members were Individual Ordinary Members and so had a perfect right to participate in the Group's actions. A. Daneels announced that the Group was near to establishing a prototype for power convertor protocols helped by the gifts of work stations from Digital Corporation and Hewlett-Packard (which Council was pleased formally to accept). Its other main projects concerned: instrumentation for power convertors; the establishment of instrumentation applications software, which could save in CERN alone many tens of manyears of programming effort; a workshop on real-time kernels for micro-processor based systems; their 2nd international conference which will be cosponsored by IEEE.

The Interdivisional Group on Physics for Development is also gaining in strength although the number of IOMs who have expressed a wish to join it is perhaps surprisingly small in view of the generally expressed interest in helping less fortunate countries. In addition to mid-wifing a number of collaborative operations, the IGPD is holding a workshop on microprocessors in Turkey and is planning an annual school in Prague on experimentation for third world participants. With more funds, E. Lillethun told us more could be done and sponsorship is being actively sought.

\section{Advisory Committees}

Subsequent to the President's report the Advisory Committee on Physics Education had met and had drawn up a short list of names of new Editorial Board members of the European Journal of Physics, developed their programme of study conferences and had examined the relation between EPS and the Physics Olympiad. For EPS to be visible J. Depireux insisted, it had to do more than observe. The recommendation was made that EPS should donate a prize like the others, more symbolic than really valuable - for best combined performance in theory and experiment. Council approved.

The Advisory Committee on Physics and Society had met under its new Chairman, E.W.A. Lingeman (completing his term as EPS Treasurer and replacing Sir Alec Merrison whose recent death Council deplored). The follow-up to the very successful East-West Workshop on Nuclear Winters will be a Study School on Induced Critical Conditions in the Atmosphere at the Villa Gualino at the end of September. Recalcitrant societies were urged to put forward the names of their experts as a matter of urgency. A workshop is also being planned on atmospheric balances related to energy problems.

The acting Chairman of the Publications Committee - your editor - reported on its latest initiative following the expert analysis of the word-processor survey made with the help of five publishers of EPS Recognized Journals. This had shown that the variety of formatting systems used was even more complex than at first thought. An experiment is now to be made by CERN and North-Holland to see how practicable it would be for authors to mark up on the ASCII data file of their particular system the SGML tagging code. The results will be compared with the experience of other publishers who have agreed to accept electronic MSS prepared on a particular system.

J.A. Goedkoop as Chairman of ACAP$\mathrm{PI}$ reported on the recent meeting in Nice with delegates of the Associate Members (see page 68) and $H$. de Waard brought us up to date on the arrangements for the 8th EPS General Conference in Amsterdam, 4-8 September 1990. That seemed to be going very well with the main programme and speakers already defined.

\section{Administration}

General satisfaction was expressed with the administration of the Society but Council was much taken by the problem of using our funds locked away in non-convertible currency. It is not generally appreciated how difficult it is to transfer money (at an acceptable exchange rate) between eastern countries and it is not helpful to EPS just to spend it on local events in the country where it is held. Nevertheless there are EPS tasks that can be done in these countries and it was particularly galling that such a one - the members' booklet, due to be printed in the DDR was now well over a year late. Some success in making use of our money has been recorded in specific instances, but it has taken all the ingenuity of the Executive Secretary to bring this about.

IOM recruitment was another subject of much concern and once again the need for EPS to be visibly active and communicative was seen as the key element. Also our fee structure generally was something that needed considering. All these aspects will be much in the minds of the Review Committee when it deliberates the future of EPS.

\section{Publications}

More cheerful was the debate on our publications starting with a summary of the situation regarding the European Journal of Physics presented by the editor, J. Pisut. Whereas a few years ago, the problem was to get good papers, the initiative taken to sollicit more contributions and introduce clusters of papers had produced its results and monthly publication was now being contemplated. Much effort had been put in of late to make the journal more readable and to increase the number of provocative and cultural articles.

This was the last occasion when Nicholas Kurti would present the report on Europhysics Letters. In characteristic style he recounted the growth of the journal, the early problems generated by its own success, the fight against the back-log that built up, and the unevenness that still existed in subject coverage and circulation. Council responded, after delving into the details, with warm applause for a job well done and offered its best wishes to the new Editor-inChief, Werner Buckel.

Studies on the future of Europhysics News were presented by M. Jacob. The Working Group had been looking at the possibilities of making a big increase in the size of the journal with a view to its becoming self-supporting through subscriptions and advertising. However, whether such a move was made as a growth function, as a new exercise in collaboration with a benevolent publisher or with an existing national journal, there had to be a big increase in news from the Society. This in turn demanded more activity in the Society and a steady flow of information from its component bodies. The Editor recalled the similar problem that had faced the Society from its inception and the reasons which led to the production of Europhysics News in its present form. Europe was a very special place. As an interim measure the Chairman of the Editorial Board, J. Muller proposed adding four cover pages to brighten the appearance and to try and have the extra cost sponsored by advertisers. Council agreed the experiment should be made, but also that a new effort be made to establish an active network of correspondents in the member societies and Divisions.

June will be the big month when Europhysics News appears in its new style with a special issue on the completion of the LEP project including special articles on the accelerator, the experiments and experimental programme and some of the physics too. 


\section{New Instruments}

As announced in last month's issue, Council approved the formation of two new Interdivisional Groups, one on Accelerators and the other on the History of Physics.

Council also approved the signing of an agreement with the Regional Office for Science and Technology for Europe and N. America of UNESCO (ROSTENA) for the constitution of the European Advisory Committee on Energy Storage and Saving in the framework of the European Regional Cooperation in Science and Technology of UNESCO. A massive title for a massive subject. The main actions foreseen are:

- To establish a Network of East-West institutions.

- To publish a regular series of reports and to create a data bank covering:

i) a census of existing research activities in the area of energy storage and related materials science and technology in different countries, notably in Europe;

ii) a census of implementation activities in the area of energy storage and saving in different countries;

iii) an analysis of trends in basic research into new principles and materials for energy storage, and of perspectives for future technological applications;

iv) possible international cooperations and know-how exchanges and suggestions for the constitution of a network among academic and national institutions and industrial partners on, at least, a European scale;

v) an assessment of the impact of scientific and technological research on energy saving policies and environmental protection.

- To define the connection with largerscale initiatives of UNESCO, such as the Global Energy Programme, and smallerscale projects such as the ICTP Programme for Training and Research on Non-Conventional Energy Sources.

- To explore a possible connection to the economic communities, namely EEC and COMECON, for joint actions, e.g. organising a world-wide conference dealing with these problems.

- To promote and organize international meetings and workshops in the field.

\section{Next Meetings}

The next meetings of Council following the change in venue for 1990 are as follows:

1990: 29/30 March, Uppsala

1991: 21/22 March, Athens

1992: 26/27 March, Nice

1993: 25/26 March, Warsaw

1994: 24/25 March, Berlin or Bad Honnef
Un poste de UNIVERSITÉ DE NEUCHÂTEL

\section{Professeur ordinaire de physique théorique}

est à repourvoir (poste complet).

Les domaines de recherche de l'Institut de physique relèvent de la physique du solide et de la physique nucléaire et corpusculaire. Le nouveau titulaire pourra effectuer une recherche autonome; on souhaite qu'il apporte son appui à la recherche expérimentale en physique des particules et qu'il participe à l'ensemble du cycle des cours de physique théorique conduisant au diplôme de physicien.

Entrée en fonction: avril 1990 ou à convenir.

Les demandes de renseignements peuvent être adressées au directeur de l'Institut de physique, rue A.-L. Breguet 1, CH-2000 Neuchâtel. Les candidatures doivent être présentées avec curriculum vitae, liste de publications et références, au Département de l'Instruction publique, Château,

CH-2001 Neuchâtel,

jusqu'au 31 août 1989.

\section{EPS Seminar on International Research Facilities}

What can one say about a Seminar that packs 50 lectures into $2 \frac{1}{2}$ days starting at $13: 30$ on Friday afternoon and finishing at 17:30 on the Sunday and which includes parallel sessions on the Saturday morning - except that it was numbing. And just to make sure that participants started the course in the right frame of mind, there had been two scientific lectures after the first days meeting of Council and straight after Council finished we were all invited to hear the lecture given by Prof. van Lieshout on the Role of European Organisations in the Promotion of Science and Technology at the Yugoslav Academy on the Thursday evening. Van Lieshout talked mainly of the growing role of the European Science Foundation, especially through the network programme, and the founding of the Academia Europaea in September 1988, roughly modelled on the British Royal Society and designed to grow finally to about $\mathbf{5 0 0 0}$ members.

It was a pity that the main Seminar programme was so full and included papers outside the subject as well as being in part repetitious as almost no time was left for serious discussion. This was particularly regrettable as many of the top people were there and perhaps we might have heard some thoughts on alternative solutions or relative priorities. For example, we heard four too brief descriptions of the main line tokamak programmes, in addition to the Japan programme, two persuasive talks on inertial fusion - one on heavy ion and the other on laser systems (in one of the parallel sessions), but no time to look at the pros and cons or assess the scale of effort needed to study them properly certainly no time to make comparisons and not a thing on muon catalysed fusion (see page 61). (Electro-chemical induced fusion broke later.) A real opportunity was lost of doing a little re-thinking on the relation between fusion and plasma physics to see how best to get the big experiments off the "clean power tomorrow" hook on which they have been hung for far too long.

Undoubtedly the Proceedings of the Seminar which the Chairman of the Organising Committee, Prof. I. Slaus,

\section{Postdoctoral Positions in STM}

The Universities of Namur (Belgium), Leuven (Belgium) and Salford (United Kingdom) have several research positions at the postdoctoral level for experimental physicists, chemists or electrical engineers to work on projects involving scanning tunnelling microscopy and spectroscopy. Experience in ultra-high vacuum technology or surface science would be an advantage. The positions, sponsored by the respective institutes, national funding bodies and a stimulation programme of the EEC are for a maximum of three years and are available immediately. (Some positions require EEC citizenship.)

Applications to: Prof. A. LUCAS, FUNDP,

61, rue de Bruxelles, B-5000 Namur, Belgium.

Tel. ++ 32 (81) 229061 . 